\title{
PENGARUH PEMBERIAN ASI TERHADAP PERKEMBANGAN ANAK USIA 6 - 12 BULAN DI RW 04 DESA SAMBIBULU \\ KECAMATAN TAMAN SIDOARJO
}

*Ayun Nif'ah, **Firdaus

(Stikes Yarsis, J1. Smea 57 Surabaya)

e-mail: firdausbakdil@yahoo.co.id

\begin{abstract}
Abstrak : Penelitian ini untuk mengkaji pengaruh pemberian ASI terhadap perkembangan anak usia $6-12$ bulan di RW 04 Desa Sambibulu Kecamatan Taman Sidoarjo. Desain penelitian adalah analitik retrospektif study. Populasi penelitian ini adalah 29 pasang ibu beserta anak usia 6 - 12 bulan di RW 04 Desa Sambibulu Kecamatan Taman Sidoarjo dan besar sampel 27 pasang responden, diambil dengan simple random sampling. Variabel independen adalah pemberian ASI dan perkembangan anak sebagai variabel dependen. Instrumen pengumpulan data mengunakan kuesioner dan checklist KPSP kemudian dilakukan uji statistik Mann Whitney dengan tingkat kemaknaan $\alpha=0,05$. ada pengaruh pemberian ASI terhadap perkembangan anak $\rho=(0,000)<\alpha=(0,05)$
\end{abstract}

Abstract: This research is to observe the purpose of this study was to analyze the influence of breastfeeding toward the development of children aged 6 - 12 months living in RW 04 Sambibulu Village, Taman Subdistrict, Sidoarjo. The design of research was analytic retrospective study. The population involved 29 couples with their children aged 6 - 12 months living in the above mentioned region. The simple random sampling technique was used to take 27 couples as the samples of research. The independent variable of this research was breastfeeding, whereas the dependent one was the child's development. Questionnaires of breast and checklist of KPSP (Pre Screening Questionnaire for Child Development) were used to collect the data which analyzed by using Mann-Whitney's statistic test with the significance level $\alpha=0.05$, it means that there was a relationship between breastfeeding and the development of children $\mathrm{p}(0.000)<\alpha(0.05)$

Kata kunci : ASI, Perkembangan, anak

\section{PENDAHULUAN}

Anak merupakan aset bangsa yang sangat berharga dan menjadi penerus cita - cita bangsa yang nantinya akan menjadi pemimpin di masa depan yang meneruskan kemajuan bangsa dan Negara. Namun sebagai aset berharga, tidak

semua anak memperoleh haknya untuk dapat berkembang sebagaimana layaknya anak pada umumnya. Hal ini salah satunya dialami oleh anak - anak yang ketika ia masih bayi tidak diberikan ASI oleh ibunya.

ASI merupakan nutrisi dengan kualitas dan kwantitas yang terbaik bagi bayi, pemberian ASI di Indonesia saat ini belum dilaksanakan sepenuhnya, karena upaya meningkatkan perilaku menyusui pada ibu yang memiliki bayi khususnya pemberian ASI yang masih kurang. ASI 
mengandung unsur-unsur gizi yang dibutuhkan oleh anak agar anak dapat berkembang secara optimal (Khamzah, 2012). Pemberian ASI diatur dalam UU Kesehatan Tahun 2009 Pasal 128 dan Pasal 129 yaitu setiap bayi berhak mendapatkan ASI sejak dilahirkan selama 6 (enam) bulan, kecuali atas indikasi medis. Ketika anak berusia lebih dari 6 (enam) bulan dberikan susu formula dan diperkenalkan makanan pendamping, akan tetapi pemberian ASI tetap dilakukan agar perkembangan anak tetap optimal. Dalam Al Qur-an juga menyebutkan masalah menyusui seperti dalam surat Al Baqarah ayat 233 : "Hendaklah para ibu menyusui anak-anaknya selama dua tahun penuh yaitu

bagi ingin menyempurnakan penyusuan", tetapi pada kenyataannya ibu $\quad$ ibu dimasyarakat belum memberikan ASI pada anaknya sampai anak tersebut berusia 2 tahun, bahkan banyak ibu yang menikah diusia dini dan tidak memberikan ASI pada anaknya sejak dini.

Anak yang mendapatkan ASI sejak dini umumnya mengalami perkembangan dengan cepat dibandingkan dengan anak yang hanya mendapatkan susu formula karena pada anak yang hanya mendapatkan susu formula biasanya mengalami perkembangan yang kurang atau terlambat dan akan mempengaruhi kualitas anak.

Hal ini disebabkan karena ibu sibuk bekerja, bentuk payudara menjadi tidak

indah, ASI tidak cukup, ASI tidak keluar, serta susu formula itu dianggap lebih praktis. Padahal seorang ibu mempunyai kewajiban yang penting yaitu dengan mendidik anaknya melalui pemberian ASI yang merupakan hak dari anak yang akan berpengaruh terhadap perkembangan anak (Khamzah, 2012).

Survey DinKes Jatim Mei 2010 di Jatim terdapat $60,3 \%$ anak yang mengalamani gangguan perkembangan pada usia $0-3$ tahun. Penelitian yang dilakukan Isnaini (2012) di RW 04 Desa Bambe Kecamatan Driyorejo Gresik tentang perkembangan anak dari 40 anak didapatkan $7 \%$ mengalami

perkembangan kurang, 39,5\% mengalami perkembangan cukup. Berdasarkan

pengambilan data awal peneliti di RW 04 Desa Sambibulu Kecamatan Taman Sidoarjo pada bulan November 2012 pada 5 anak usia 6 - 12 bulan didapatkan 1 anak mengalami perkembangan yang baik atau optimal, secara kebetulan anak tersebut mengkonsumsi ASI eksklusif, sedangkan 3 anak yang mengkonsumsi ASI dan susu formula mengalami perkembangan yang cukup dan 1 anak yang hanya mengkonsumsi susu formula mengalami perkembangan yang kurang. Perkembangan anak (motorik halus, motorik kasar, bahasa, dan sosial) dipengaruhi oleh pemberian ASI sejak dini, jikaperkembangan anak tidak optimal atau tugas perkembangan tertentu tidak dapat dicapai, maka dapat berefek pada

penilaian yang kurang menyenangkan dari lingkungan sosialnya, sehingga dasar untuk penguasaan tugas - tugas perkembangan berikutnya menjadi tidak adekuat (Soetjiningsih, 2012). Pada masa ini (6 - 12 bulan) perkembangan anak berlangsung sangat pesat (ekplosif) sehingga 
pemberian ASI sangat di butuhkan untuk menentukan kualitas anak di masa depan.

Petugas kesehatan khususnya pada perawat berkewajiban memberikan

penyuluhan tentang pentingnya pemberian ASI kepada anak minimal sampai anak 6 (enam) bulan. Pada ibu yang melakukan pasca persalinan, petugas

kesehatan tidak diperbolehkan mengajarkan pemberian susu formula apalagi pada anak - anak yang belum cukup umur. Selain itu petugas kesehatan atau perawat juga berkewajiban mengajarkan perawatan payudara agar ASI dapat keluar dengan lancar. Dengan demikian ibu akan memberikan ASI pada anak sejak dini dan perkembangan anak (motorik halus, motorik kasar, bahasa, dan sosial) juga dapat berkembang seoptimal mungkin Dengan permasalahan diatas, maka perlu dilakukan penelitian tentang "Pengaruh pemberian ASI terhadap perkembangan anak usia $6-12$ bulan di RW

04 Desa Sambibulu Kecamatan Taman Sidoarjo"

\section{METODE}

Desain penelitian

Jenis rancangan dalam penelitian ini adalah analitik korelasi dan rancangan

yang digunakan adalah Retrospektif Study yaitu suatu jenis penelitian yang

melihat ke belakang artinya pengumpulan data dimulai dari akibat yang telah terjadi atau variable dependen (perkembangan anak) ke variable independen (pemberian ASI).

Populasi dan Sampel

Populasi dalam penelitian ini adalah ibu yang mempunyai anak usia 6 - 12 bulan di RW 04 Desa

Sambibulu Kecamatan Taman Sidoarjo sebesar 29

pasang responden. Sampel dalam penelitian ini adalah sebagian ibu yang

mempunyai anak usia $6-12$ bulan di RW 04 Desa Sambibulu Kecamatan Taman Sidoarjo. Besar Sampel adalah 27 ibu yang mempunyai anak usia 6-12 bulan . Teknik pengambilan sampel dalam penelitian ini adalah menggunakan teknik simple random sampling, yaitu suatu teknik pengambilan sampel yang dilakukan secara acak. Penelitian ini dilakukan di RW 04 Desa Sambibulu Kecamatan Taman Sidoarjo sebanyak 27 pasang responden. dengan alasan pemberian ASI kepada anak usia $6-12$ bulan di tempat tersebut masih kurang. Peneliti berkunjung ke rumah rumah warga, lalu di rumah warga peneliti mengadakan pendekatan kepada anak beserta ibu tersebut yang menjadi sampel. Metode yang digunakan untuk pengumpulan data dengan menggunakan kuesioner yang dibagikan kepada ibu yang mempunyai anak usia $6-12$ bulan. Responden cukup mengisi pertanyaan yang sudah tersedia pada lembar kuesioner adapun lembar check list di isi peneliti sesuai tahapan yang sudah di capai anak melalui pertanyaan yang di ajukan kepada ibunya dan pengamatan langsung.

\section{HASIL DAN PEMBAHASAN}

\section{a. Hasil}

Penelitian ini di dilakukan di RW 04 Desa Sambibulu Kecamatan Taman Sidoarjo. Dari hasil penelitian didapatkan dari 13 responden yang diberikan 
ASI didapatkan hampir setengahnya $(48,1 \%)$

perkembangan anaknya sesuai, sedangkan dari 14 responden yang tidak memberikan ASI didapatkan sebagian besar (51,9\%) perkembangan anaknya menyimpang.

Dari hasil uji statistik Mann Whitney menggunakan SPSS 17 dengan tingkat $=0,05$ didapatkan hasil $\square$ kemaknaan Asymp. Sig. (2-tailed) 0,000) $\square \square \square<0,05$ maka dapat disimpulkan bahwa $\mathrm{H}_{0}$ ditolak artinya ada pengaruh antara pemberian ASI terhadap perkembangan anak usia 6 - 12 bulan di RW 04 Desa Sambibulu Kecamatan Taman Sidoarjo.

\section{b.Pembahasan}

Pada pembahasan ini peneliti akan mengguraikan hasil penelitian tentang Pengaruh Pemberian ASI Terhadap Perkembangan Anak Usia $6-12$ bulan Dari hasil penelitian yang dilakukan di RW 04 Desa Sambibulu Kecamatan menunjukkan pemberian ASI anak sangat penting terhadap berkembangan anak. Dari hasil penelitian didapatkan 14 responden (ibu) yang tidak memberikan ASI pada anak, sehingga hampir semua $(92,9 \%)$ perkembangan anak menyimpang. Menurut Khamzah (2012), pemberian ASI merupakan hal penting dalam tumbuh kembang anak karena di dalam ASI terdapat kandungan minyak omega-3 asam linoleat alfa yang sangat dibutuhkan bagi perkembangan anak dan tidak terdapat pada susu formula . Anak yang mendapatkan ASI sampai berusia 6 bulan akan lebih cepat berkembang dibandingkan dengan anak yang tidak diberikan ASI karena ASI mengandung unsurunsur gizi yang dibutuhkan oleh anak agar anak dapat berkembang secara optimal. Pemberian ASI berperan penting terhadap perkembangan anak sesuai dengan tahapan usianya, jika pemberian ASI pada anak kurang maka perkembangan anak cenderung akan menyimpang. Berdasarkan wawancara didapatkan bahwa ibu juga kurang mendapatkan informasi tentang manfaat ASI, malah yang ibu dapat adalah informasi seputar susu formula yang banyak ibu jumpai di televisi, radio, dan majalah sehingga ibu tergiur pada iklan tersebut dan memilih susu formula daripada ASI.

Menurut Wong (2008) usia yang paling memuaskan untuk membesarkan anak adalah antara 18 dan 35 tahun. Usia orang tua akan sangat mempengaruhi kesiapan dalam memberikan pola asih atau sikap kebiasaan dalam menyusui anaknya. Namun hal ini bertentangan dengan fakta di lapangan karena pada usia tersebut ibu cenderung lebih mementingkan penampilannya atau takut bentuk payudara menjadi tidak indah lagi sehingga ibu lebih memilih memberikan susu formula daripada ASI.

\section{Simpulan}

Berdasarkan hasil penelitian dan pembahasan hasil penelitian dapat disimpulkan bahwa Ada pengaruh pemberian ASI terhadap perkembangan anak usia $6-12$ bulan RW 04 Desa Sambibulu Kecamatan Taman Sidoarjo .

Bagi ilmu keperawatan diharapkan untuk lebih sering lagi memberikan penyuluhan kepada ibu tentang pentingnya pemberian ASI supaya ibu dapat 
memberikan ASI minimal sampai anak berusia 6 bulan agar perkembangan anak bisa tercapai secara optimal. Dan bagi diharapkan agar memberikan ASI pada anak minimal sampai anak berusia 6 bulan dan mencari banyak informasi tentang usianya.

\section{DAFTAR RUJUKAN}

Agus. C. Dr. 2008. Kuesioner Pra Skrining Perkembangan KPSP.http://balitakami.wordp ress.com. Diakses 28 Januari 2013

Al-Qur'an dan Terjemahan. Al Baqarah ayat 233. Haekal Media Center.

Bandung 2007

Arifin, Siregar. 2004. FaktorFaktor yang Mempengaruhi Pemberian ASI oleh Ibu Melahirkan. www.library.usu.ac.id.

Artikel diakses tanggal 28 Januari 2013

Deteksi Dini Tumbuh Kembang Anak di Tingkat Pelayanan Kesehatan Dasar .

Jakarta, Departemen

Kesehatan Republik Indonesia

Hidayat, Aziz Alimul A. 2008. Pengantar Ilmu Keperawatan Anak 1. Jakarta, Salemba Medika.

Khamzah, Siti, N. 2012. Segudang keajaiban ASI, Yogjakarta , FlashBook

Narendra, M.B., Sularyo, T., Soetjiningsih, Suyitno, H., Gde Ranuh (2002).Buku

Notoatmodjo Soekidjo (2010). Metodologi Penelitian Kesehatan. Jakarta: Rineka perkembangan anak mereka sesuai dengan tahapan usianya. Dengan demikian deteksi dini dan intervensi dini sangat membantu agar tumbuh kembang anak dapat seoptimal mungkin sesuai dengan tahapan

Cipta.

Nursalam. 2008. Konsep dan Penerapan Metodologi Penelitian Ilmu Keperawatan. Jakarta, Salemba Medika.

Prasetyono, Sunar, D. 2009. Buku Pintar ASI Eksklusif. Yogyakarta, Diva Press 56

Poedianto, Handajani D. 2002. ASI dan Ibu Bekerja.Ayah Bunda. Jakarta. PT. Apirasi

Pemuda.

Santrock, John. W. 2007. Perkembangan Anak Edisi Ke sebelas Jilid I. Jakarta,

Erlangga.

Santrock, John. W. 2007. Perkembangan Anak Edisi Ke sebelas Jilid I. Jakarta, Erlangga.

Soetjiningsih. 2012, Tumbuh Kembang Anak, Jakarta, EGC Suryanto, 2007. Informasi dan Pengetahuan. www. suryanto. blogspot. co. Id/html diakses 27 Maret 2013

Tagor, Rosita A. (2007).

Perkembangan Anak 3 Tahun Pertama yang Menentukan. Jakarta, Gaya Favorit Press.

Wong L. Donna dkk (2008). Buku Ajar Keperawatan Pediatrik Wong, Ed.6, Vol. Jakarta : EGC

Yuliarti, Nurheti. 2010. Keajaiban ASI . Yogyakarta, KDT 